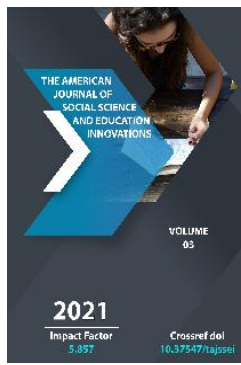

Journal Website: http://theamericanjour nals.com/index.php/taj ssei

Copyright: Original content from this work may be used under the terms of the creative commons attributes 4.0 licence.

\section{Identification Of Forms And Means Of Physical Activity During Military Of Students Of Military Education Faculty}

\author{
A.T.Khasanov \\ Philosophic Doctor (PhD), Fergana State University, Uzbekistan \\ G.R.Kurbanov \\ Head Teacher, Fergana State University, Uzbekistan \\ M.K. Ruzieva \\ Teacher, Fergana State University, Uzbekistan \\ F.X.Orifjonov \\ Uzbekistan State University Of Physical Education And Sports 3 Course, Uzbekistan
}

\title{
ABSTRACT
}

The article highlights the effectivness of the training methodology that is based on expirience and has been developed to enhance the quality of professional training required during the training sessions with the students of the Military Education Faculty.

\section{KEYWORDS}

Training sessions, innovational activity, physical training, military training, complex training, exercises technique.

\section{INTRODUCTION}

An important task of the higher education system is to radically improve the system of higher education, to radically restructure the content of training based on the prioraties of socio-economic development of the country, to train specialists with higher education in accordance with international standarts.

This highlighted the need to organize a high level of professional, practical and physical training of students and future military educators. Without such training, it is impossible to form and develop in students the socially necessary qualities that enable them to act consciously and confidently in any day-to-day and extreme situation of military service.

In order to achive the goal of forming the knowladge, skills and qualities of the individual, it is necessary to model the structure of the innovative activity of the process of professional formation of the specialist. The preparation of teachers for innovative activities can be based on a systematic and active creative approach. 
This approach ensures that the pre-service military training process is integrated.

Summer training sessions for third-year students are also important for improving students ' professional and physical fitness and comprehensive training. Creating a rational system of physical education during the training sessions will allow students to maintain the necessary level of physical fitness and maintain their physical qualities at the beginning of the new period.

At this stage of research, the task is to determine the strict implementation of regular physical training in a particular military garrison. Given this situation, we tried to identify the most appropriate forms and means of teaching and to assess the attitude of students of them.

\section{Organization of expirience:}

The expiriment was organised in accordance with the requirements of the Faculty of Military Education of Fergana State Unversity. The control course students participated in the expiriment; one group of students formed the expirimental group and the other one formed the requirements control group.

During the pedagogical expiriment, various forms of physical education were used. Morning gymnastics options were offered and they are as follows

- Load size

- The composition of the means used

- Differed in ways of organization.

The main criterion for the size of the load was the time spent on morning gymnastics, which was determined by the number of exercises included in the complex and the number of repetitions . in all cases, the engine density remained almost constant and exceeded by $80 \%$.

Three variants of morning gymnastics were tested;

The first lasted 12-15 minutes .

The second lasted 25-30 minutes .

The third lasted up to 40 minutes .

The different variants of morning gymnastics differed in content by two signs .

Firstly, according to the composition of the means used;

Secondly, the ratio of the number of individual exercises to the number of repetitions.

Three training optionswere tested according to the composition of the tools used.

1) Physical training consisting only of general developmental exercises

2) The exercises mentioned in the first paragraph plus strenght exercises

3) Exercises mentioned in the first and second paragraphs, plus a 15-minute run.

According to the number of exercises and repetition measure two variations are tested:

1. The number of repetition of an exercises 12-29times (this variation ia recommended in many content in primary gymnastics.

2. The measure of repetition of an exercises till 100-150times (this kind of recommendation is given by academic A.A. Miculin ) and as well as some suitable exercises.

Four variations are used according to the organising ways: 
1) A group body exercises for all students who live in the dormitory

2) Exercising with group

3) Individual gymnastics to do independently

4) Combined shapes of orginising.

At fisrt, the first part is done as a group and ended independently

\section{Evening classes.}

In the process of pedagogical practice, it was found that physical education classes, which differ in the method of organization, content and volume of physical activity, are strictly implemented . according to the method of organization, academic-type classes were compared, in which the participation was mandatory, the content of which was strictly defined, and students in this area were suitable for physical education programs, classes in sports sections.

The most popular types of training ; athletic running, gymnastics, fitness running, volleyball with simplified rules, mini-football. The size and duration of the loading was determined by the participants self regulation`. As for the content of the training, they were largely determined by the material and technical base of the military garrison.

Experience results. A comparison of the morning gymnastics options, which differed in size, found that training was less suitable for the mass introduction of physical education. It included a 40-50 minute run and a 10-15 minute run in the second section. It turrned out that $76.4 \%$ students were against it, and only athletes with a sports category in the chosen sport gave a positive assessement of this type of physical education.
When students were asked which "major" or "minor" physical education they prefer, 38.3\% of students voted for "small" physical education, $31.2 \%$ voted for large physical education, and the remaining 30.5\% chose both forms of physical education.

As for the composition of the tools used, most students tried all the options of morning gymnastics and chose the option of morning gymnastics with strength exercises. $74.6 \%$ of students who asked to create such a complex of morning gymnastics exercises supported it, $12.3 \%$ of students preferred light gymnastics. There are no strength exercises, and the remaining $13.1 \%$ of students could not agree on this issue.

Additional physical education classes were organized for the students of the experimental group during the academic year. They were held up to five times a week. The composition of the tools used was aimed at improving endurance, power and speed.

It is important to focus on the methodology of these exercises. Here, endurance running was standardized for 10,15 or 20 minutes in the first week. In this case, the requirements were given the oppotunaty to freely choose the peace of running when they received enough physical load, but did not feel graet fatigue.

In the second week, the running duration remained the same as before, but the result was evaluatedover time. Over the next two weeks, test items were adopted as test guidlines.

During the training sessions, we measured the physical fitness of the students four times, the peagogical testing of the movement readiness of their requirements was conducted before going to the summer camp in July and was 
The American Journal of Social Science and Education Innovations

(ISSN - 2689-100x)

Published: June 27, 2021 | Pages: 79-83

Doi : https://doi.org/10.37547/tajssei/Volume03lssue06-13

2021: 5.857

accepted as the first indicator. The follow-up surveys were conducted each weekend and at the end of the training session (1-schedule/ diagramm).

Identification of forms and means of physical activity during military of students of military education faculty

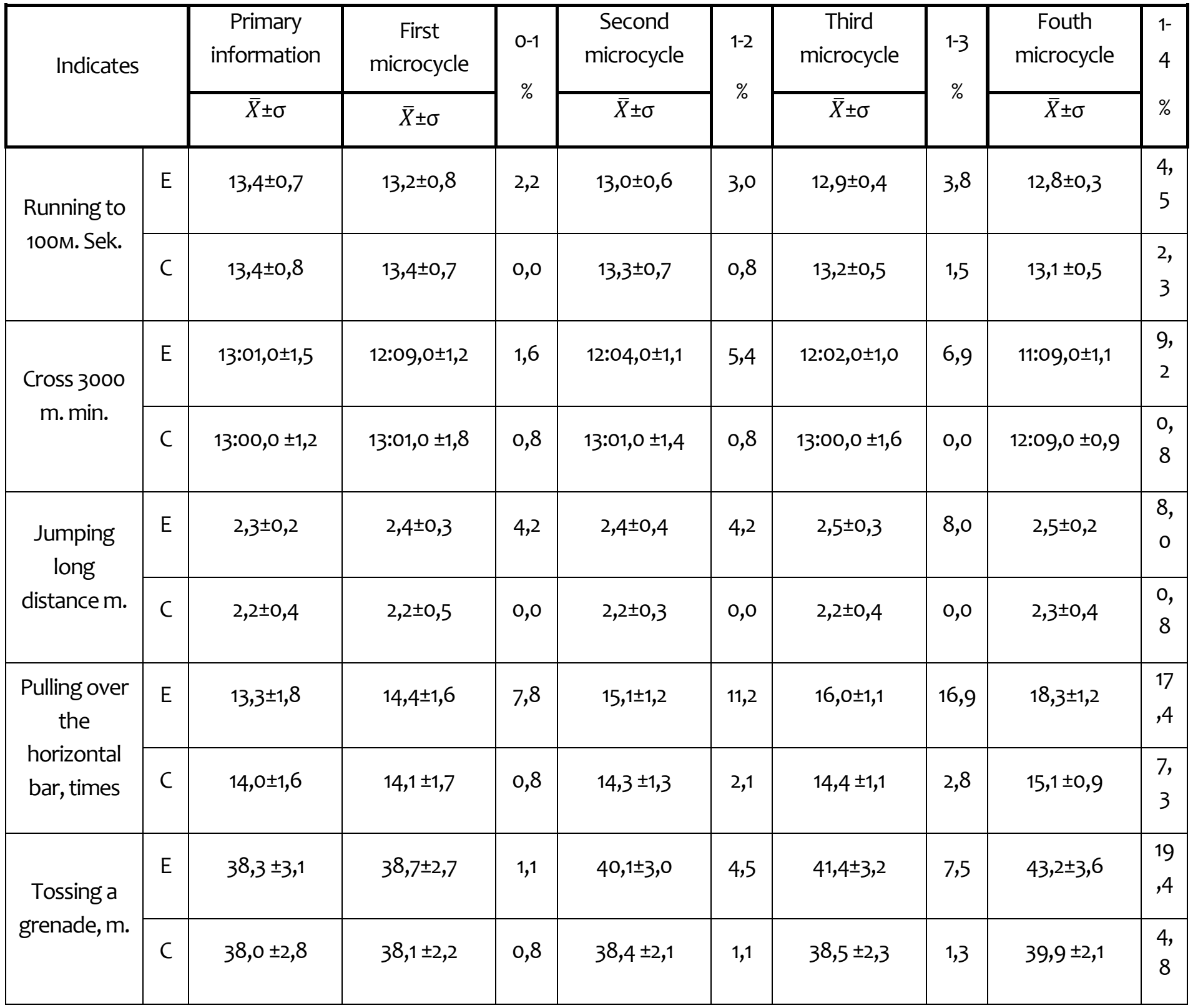

The growth of key physical attributes in the experimentalgroups was statistically higher than in the control groups. The effectivness of the method, aimed at improving the professional skills of third-year students during a single mesoycle fieldworl, is $4.5 \%$ in 
the 100-meter run, $9.2 \%$ in the 3000-meter croos run, $8 \%$ in the long jump, $27.4 \%$ in the horizontal bar and $11.4 \%$ in the grenade throw. And can be used in the practise of physical eucation for students of the Faculty of Military Education.

During the training session, in order to increase the motivation for professional and physical training, it is necessary to conduct daily tests on 100 meters running, 3000 meters croos run, jumping from standing position, pilling on a horizontal bar, throwing a grenade.

\section{REFERENCES}

1. The President's of the Republic of Uzbekistan "Resolution about developing of Higher Education" PD 29-2909 decision Tashkent, 2017 April 20.

2. Khankeldiev Sh., Khasanov A. Experimental substantiation of the directed methodology of physical education of students of the military faculty during the summer training camp. Theory and methodology of physical education.Alma-ata. Khazakh Academy of Sports and Tourism № 2 2010. P.45-48.

3. Mikulin A.A.Active longevity.Ed. "MYTH" Dec 2019.

4. Khasanov A., Yusupov T. Allomov E. Training of specialists of the facultyof militry education for professional and innovative activities. The European Journal of Humanities and Social Sciences. Vienna. №. 1 2020. 108-113 pages. 